\title{
Экспериментальное изучение применения церулоплазмина для предотвращения ишемически-реперфузионного повреждения в кожном лоскуте
}

\author{
М. М. Сеид \\ Медицинский факультет Университета Еге, Турция

\section{Experimental studying of cerulloplasmin application for prevention of ischemically-reperfusion damage in cutaneous flap}

\author{
M. M. Seid \\ Medical Faculty of Ege University, Turkey
}

\begin{abstract}
Реферат
Цель. Изучить в эксперименте эффективность церулоплазмина, применяемого для полного устранения или минимизации ишемически-реперфузионного повреждения, вызывающего некроз кожного лоскута (КЛ).

Материалы и методы. Исследования проведены на 32 белых крысах-самцах линии Sprague Dawley массой тела в среднем 250 г. Животные разделены на 2 группы: группа I (контрольная, $\mathrm{n}=8$ ) - интактные животные; группа II (экспериментальная, $\mathrm{n}=24)$. В свою очередь группа II разделена еще на три группы: IIA, IIБ и IIB. Животным группы IIA церулоплазмин не применяли, ишемию не создавали, но забор КЛ производили. Животным группы ІІБ церулоплазмин также не применяли. Этим животным за 30 мин до создания ишемии внутрибрюшинно делали инъекцию сыворотки. Через 30 мин после инъекции на эпигастральные вены и артерии с двух сторон накладывали клипсы на 10 ч. Через 10 ч после появления в лоскуте признаков ишемии клипсы извлекали, артериовенозный кровоток восстанавливался. После этого КЛ проленовыми нитками пришивали к своему месту. Животным группы IIB за 30 мин до ишемии внутрибрюшинно вводили 60 мг/кг церулоплазмина. После инъекции церулоплазмина на эпигастральные артерии и вены с двух сторон накладывали клипсы, которые по истечении 10 ч извлекали.

Результаты. Некротический участок КЛ в группе IIА составил в среднем $(1,8 \pm 0,6)$ см, IIБ - $(22,4 \pm 3,6)$ см, IIB - $(4,1 \pm$ 1,1) CM.

Ключевые слова: реконструктивная хирургия; ишемия; некроз; белая крыса.

Abstract

Objective. To study in experiment a cerulloplasmin efficacy, applied for complete elimination and minimization of ischemically-reperfusion damage, causing necrosis of cutaneous flap (CF).

Materials and methods. On 32 white male rats of the Sprague Dawley line with the body mass $250 \mathrm{~g}$ at average the investigations were conducted. The animals were divided into two Groups: Group I (control, $\mathrm{n}=8$ ) - intact animals; Group II (experimental, $n=24$ ). Group II was divided into three Groups: IIA, IIБ and IIB. In the animals of Group IIA cerulloplasmin was not applied and ischemia was not created, but the CF was not taken. In animals of Group IIБ cerulloplasmin also was not applied. To them $30 \mathrm{~min}$ before ischemia and with objective of its creation a serum was injected intraperitoneally. In $30 \mathrm{~min}$ after injection from two sides the clipses were put on epigastric veins and arteries for $10 \mathrm{~h}$. In $10 \mathrm{~h}$ after initiation of ischemia in the flap the clipses were removed, and arterio-venous blood flow restored. Afterwards CF was sutured, using prolene threads, to its own place. Cerulloplasmin was injected intraperitoneally in dose $60 \mathrm{mg} / \mathrm{kg}$ to animals of Group IIB $30 \mathrm{~min}$ before ischemia. After injection of cerulloplasmin the clipses were put on epigastric arteries and veins bilaterally, and in $10 \mathrm{~h}$ they were removed. Results. Necrotic site of CF in Group IIA have constituted $(1.8 \pm 0.6) \mathrm{cm}$ at average, ІІБ $-(22.4 \pm 3.6) \mathrm{cm}$, and IIB $-(4.1 \pm 1.1)$ $\mathrm{cm}$.

Keywords: reconstructive surgery; ischemia; necrosis; white rat.
\end{abstract}

Существует множество способов пластики дефектов мягких тканей организма и материалов для протезирования, которые используются в клиниках, но каждому из них в равной степени присущи определенные недостатки [1].

Для пластики мягких тканей широко используются аутоткани. Несвободная, или связанная, пластика на питающей ножке предусматривает связь выкроенного тканевого лоскута с исходным ложем до тех пор, пока перемещенная часть полностью не врастет в новое место $[2,3]$. Выраженное нарушение кровоснабжения, неизбежно развивающееся в дефектах кожи и мягких тканей, свидетельствует о том, что использование хорошо кровоснабжаемых тканей является наиболее целесообразным методом пластики.

В настоящее время в арсенале хирургов имеются не только традиционные методы пластических операций, но и различные виды лоскутной пластики с использованием микрохирургической техники, которое позволяет выполнять пересадку кровоснабжаемых комплексов тканей у пациентов с дефектами тканей разных размеров и локализации. Эти методы более надежны, эффективны и экономичны, чем традиционные, но они технически сложны, трудоемки и продолжительны, харак- 
теризуются обширными доступами, длительной анестезией и большими рисками неэффективности [4]. Данная проблема актуальна в связи с ограниченной частотой применения таких методов.

Цель исследования: изучить в эксперименте эффективность церулоплазмина, используемого для полного устранения или минимизации ишемически-реперфузионного повреждения, вызывающего некроз КЛ.

\section{Материалы и методы исследования}

Экспериментальные исследования проведены в научно-исследовательском центре университета Джелал Баяр на 32 белых крысах-самцах линии Sprague Dawley массой тела в среднем 250 г. Всех животных содержали в виварии в стандартных условиях: крысы находились в одной клетке, кормили их с использованием стандартной лабораторной диеты, потребление воды было свободным, за исключением последних 12 ч до проведения эксперимента, когда потребление воды ограничивали. Температура воздуха в помещении - $(24 \pm 1){ }^{\circ} \mathrm{C}$. Для анестезии использовали внутримышечно 50 мг/кг кетамина (Турция), для седации и аналгезии - 15 мг/кг ксилазина (Нидерланды). Все оперативные вмешательства выполнены одним хирургом.

Методом случайной выборки животные разделены на 2 группы: группа I (контрольная, $\mathrm{n}=8$ ) - интактные животные, группа II (экспериментальная, n = 24). В свою очередь группа II разделена еще на три группы: IIA, IIБ и IIB.

Животным группы I не вводили церулоплазмин и не производили забор КЛ. Животным группы IIA церулоплазмин не вводили, ишемию не создавали, но забор КЛ производили. Животным группы ІІБ церулоплазмин также не вводили. За 30 мин до создания ишемии им внутрибрюшинно делали инъекцию сыворотки. Через 30 мин после инъекции на эпигастральные вены и артерии с двух сторон накладывали клипсы на 10 ч. Через 10 ч после появления в лоскуте признаков ишемии (снижение температуры, исчезновение капилляров и бледный цвет) клипсы извлекали, артериовенозный кровоток восстанавливался. После этого КЛ проленовыми нитками пришивали к своему месту. Животным группы IIB за 30 мин до ишемии внутрибрюшинно вводили 60 мг/кг церулоплазмина. После инъекции церулоплазмина на эпигастральные артерии и вены с двух сторон на 10 ч накладывали клипсы, которые по истечении указанного времени извлекали.

На 7-е сут после оперативного вмешательства оценивали жизнеспособность в общей сложности 48 КЛ, взятых у крыс группы II. КЛ фотографировали на расстоя- нии 10 см, затем вычисляли средние величины некротического участка и с использованием программы ImagePro Express сравнивали их между собой.

У всех животных группы II из правых паховых лоскутов брали кусочки кожи для биохимических анализов. Для измерения биохимических показателей - малонового диальдегида (МДА) и каталазы (КАТ) - через 24 ч после реперфузии кусочек ткани размерами $1 \times 1$ см, вырезанный в продольном направлении со свободного края лоскута ткани на ножке, помещали в фосфатно-буферный раствор.

Также были оценены гистологические показатели Кл с использованием вычисления по Verhofstad. Для этого образцы тканей фиксировали в 4\% растворе нейтрального формалина, далее их заливали в парафин. Гистологические срезы толщиной 5 - 7 мкм окрашивали пикрофуксином по Маллори, азаном, а также гематоксилином и эозином. Затем образцы исследовали под световым микроскопом (ув. ×10, 20, 40).

При морфологическом исследовании с использованием вычисления по модификации Verhofstad оценивали некроз, отек, полиморфноядерную инфильтрацию лейкоцитов (ПМЯИЛ), разрастание коллагеновых волокон (РКВ) и волосяных фолликулов (РВФ), рост мелких кровеносных сосудов (РМКС). Гистопатологические срезы в каждой группе, окрашенные азаном, по Маллори, разделяли с дальнейшим взятием из 20 различных участков кусочков эпидермиса для вычисления средних арифметических значений с использованием программы Image-Pro Express.

Для статистического анализа результатов использовали методы математической статистики. Математическую обработку результатов исследования осуществляли с помощью статистического пакета программ SPSS 20.0 для Windows. Различия между сравниваемыми величинами считали достоверными при $\mathrm{p}<0,05$.

\section{Результаты}

Вычислены средние значения и отклонения размеров участков некроза. Размеры некротического участка КЛ в группе IIA составляли $(1,8 \pm 0,6)$ см, группе IIБ $(22,4 \pm 3,6)$ см, в группе IIB - $(4,1 \pm 1,1)$ см. Для группы ІІБ по сравнению с остальными группами отклонения статистически достоверны $(\mathrm{p}<0,05)$.

\section{Обсуждение}

Уровень МДА в группе I составил $(0,8 \pm 0,2)$ нмоль/мг, в группе IIA - $(0,9 \pm 0,2)$ нмоль/мг. Статистически значимых различий между группами не наблюдали (р > 0,05). В группе ІІБ уровень МДА - $(3,6 \pm 0,9)$ нмоль/мг был вы-

\begin{tabular}{|c|c|c|c|c|c|c|c|c|c|c|c|c|}
\hline \multirow{3}{*}{ Группы } & \multicolumn{12}{|c|}{ Гистологические показатели } \\
\hline & \multicolumn{2}{|c|}{ некроз } & \multicolumn{2}{|c|}{ отек } & \multicolumn{2}{|c|}{ пмяил } & \multicolumn{2}{|c|}{ PKB } & \multicolumn{2}{|c|}{ PBФ } & \multicolumn{2}{|c|}{ РMKC } \\
\hline & CB & $\mathrm{CO}$ & $\mathrm{CB}$ & $\mathrm{CO}$ & CB & $\mathrm{CO}$ & $\mathrm{CB}$ & $\mathrm{CO}$ & $\mathrm{CB}$ & $\mathrm{CO}$ & $C B$ & $\mathrm{CO}$ \\
\hline I & - & - & 0,12 & 0,35 & 0,25 & 0,46 & 0,25 & 0,46 & 2,62 & 0,51 & 1,37 & 0,51 \\
\hline IIA & 0,75 & 0,46 & 1,62 & 0,51 & 1,75 & 0,46 & 1,87 & 0,35 & 1,75 & 0,7 & 2 & 0,53 \\
\hline ІІБ & 2,75 & 0,46 & 3 & - & 2,87 & 0,35 & 0,87 & 0,83 & 0,37 & 0,51 & 0,25 & 0,46 \\
\hline$\| B$ & 0,25 & 0,46 & 0,25 & 0,46 & 0,12 & 0,35 & 2,75 & 0,46 & 2,75 & 0,46 & 2,87 & 0,35 \\
\hline
\end{tabular}


ше, чем в группах I, IIA и IIB, различия статистически достоверны $(\mathrm{p}<0,05)$. По уровню КАТ статистически достоверных различий между группами I и IIA не было $(1,0 \pm 0,3)$ и $(0,8 \pm 0,3)$ нкат/мг соответственно, тогда как между группой I и группой ІІБ различия по этому показателю были статистически достоверны (p < 0,05). В группе IIB уровень КАТ составил $(2,5 \pm 0,7)$ нкат/мг, МДА - $(0,2 \pm 0,1)$ нмоль/мг. По этим показателям различия между группой IIB и группами IIA и IІБ были статистически достоверны $(\mathrm{p}<0,05)$.

Средние величины (СВ) и средние отклонения (CO) гистопатологических показателей у всех животных приведены в таблище.

Для оценки заживления раны все гистологические препараты, окрашенные гематоксилином и эозином и пикрофуксином по Маллори, азаном, оценивали с использованием вычисления по модификации Vershostad. При статистической оценке полученных результатов выявлено, что церулоплазмин, введенный за 30 мин до ишемии, оказывает статистически достоверное значительное положительное действие на ишемически-реперфузионное повреждение.

\section{Выводы}

1. С целью предотвращения ишемически-реперфузионного повреждения целесообразно применять церулоплазмин до оперативного вмешательства. Он предотвращает развитие патологических процессов в тканях после реперфузии и тем самым положительно влияет на заживление КЛ.

2. Анализ данных различных моделей некроза Кл дает возможность исследователю выбрать наиболее предпочтительный способ формирования патологии в зависимости от поставленных задач.

\section{References}

1. Sergienko EN, Shhegolev AI. Polimernye materialy v vosstanovitel'noj i jesteticheskoj hirurgii lica (obzor literatury). Annaly plasticheskoj, rekonstruktivnoj i jesteticheskoj hirurgii. 2005;1:62-8. [In Russian].

2. Zelenin VN. Zameshhenie defektov tkanej loskutami s osevym krovotokom. Neposredstvennye i otdalennye rezul'taty lechenija: Avtoref. dis. dokt. med. nauk. Irkutsk; 2004:43 s. [In Russian].

3. Floris G, Medda R, Padiglia A, Musgi G. The physiophatological significance of ceruloplazmin. A possible therapeutic approach. Biochem Pharmacol. 2000;60(12):1735-41. [In Russian].

4. Jejubov JuSh, Istrinov AL. Osobennosti mikrohirurgicheskoj peresadki svobodnyh revaskulizirovannyh autotransp-lantatov pri odnovremennom ispol'zovanii metoda svobodnoj kozhnoj autoplastiki. Annaly plasticheskoj, rekonstruktivnoj i jesteticheskoj hirurgii. 2004;1:36-40. [In Russian]. 